\title{
CONSERVAÇÃO DA NATUREZA E GESTÃO INTEGRADA NO MOSAICO SERTÃO VEREDAS PERUAÇU - NORTE DE MINAS GERAIS \\ CONSERVATION OF THE NATURE AND INTEGRATED MANAGEMENT IN MOSAIC SERTÃO VEREDAS PERUAÇU - NORTH OF MINAS GERAIS
}

\author{
Geraldo Inácio Martins ${ }^{1}$ \\ ${ }^{1}$ Universidade Federal de Alagoas (UFAL), Maceio, AL, Brasil \\ Correspondência para: Geraldo Inácio Martins (geraldo.martins@penedo.ufal.br) \\ doi: 10.12957/geouerj.2018.27337 \\ Recebido em: 9 fev. 2017 | Aceito em: 31 mai. 2018
}

\section{RESUMO}

A proposta dos Mosaicos de Áreas Protegidas, enquanto estratégia de gestão ambiental, ganhou existência normativa a partir do Sistema Nacional de Unidades de Conservação-SNUC, em 2000. No entanto, estratégias de gestão integrada e territorial da conservação ambiental ultrapassam este marco normativo. A intenção deste texto é demonstrar como se constituiu a ideia dos mosaicos e como esta se tornou concreta na experiência empírica do Mosaico Sertão Veredas Peruaçu- MSVP. Para isso, metodologicamente, analisamos os documentos referentes à proposta de reconhecimento de mosaicos e sua inserção na legislação brasileira, bem como, o documento técnico de gestão do MSVP, o Plano de Desenvolvimento de Base Conservacionista - Plano DTBC, portarias de reconhecimento e os Boletins de Cooperação entre a França e o Brasil. Com este texto demonstramos as dificuldades de compatibilizar os diversos anseios e interesses que se coloca entre a conservação da natureza e as estratégias de desenvolvimento e os desafios da gestão integrada e participativa no MSPVP.

Palavras-chave: Mosaico de Áreas Protegidas; Unidades de Conservação; Gestão Integrada; Plano DTBC; Desenvolvimento de base conservacionista territorial.

\begin{abstract}
The proposal of the Mosaics of Protected Areas, as an environmental management strategy, gained normative existence from the National System of Conservation Units in 2000. However, strategies of integrated and territorial management of environmental conservation surpass this normative framework. The intention of this paper is to demonstrate how the idea of mosaics was constituted and how it became concrete in the empirical experience of Mosaic Sertão Veredas Peruaçu. For this reason, methodologically, we analyze the documents referring to the proposal of creation of mosaics and their insertion in the brazilian legislation, as well as the technical document of management of the MSVP, the Plan of Development of Base Conservationist - Plan DTBC of the MSVP, recognition orders, the Cooperation Bulletins between France and Brazil. With this text, we demonstrate the difficulties of reconciling the diverse desires and interests that exist between nature conservation and development strategies and the challenges of integrated and participatory management in MSVP.
\end{abstract}

Keywords: Mosaic of Protected Areas; Protected areas; Integrated management; DTBC Plan; Development of a conservationist base.

\section{INTRODUÇÃO}

A ideia de gestão integrada dos diversos espaços destinados à conservação da natureza, as Áreas Protegidas (ou Unidades de Conservação - UC no Brasil), surge na década de 1960 com o programa 
Man and Biosphere da UNESCO e as Reservas da Biosfera. Estas resultam da acurada crítica aos modelos tradicionais de conservação e, bem como, do reconhecimento de que criar espaços estanques para proteção é insuficiente para uma conservação em maior escala.

Aliado ao reconhecimento dos limites da conservação em espaços estanques, como o exemplo das UCs, surge também à demanda por mecanismos mais participativos e o reconhecimento da importância das comunidades locais na conservação e no manejo da natureza. Além disso, existe a constante crítica à demarcação de territórios destinados a proteção ambiental, geralmente, porque tal processo está permeado de conflitos e rompimentos de modos de vidas das comunidades atingidas e por desequilibrar os sistemas de reprodução material (tal como impedindo a expansão das áreas de agricultura, extrativismo, entre outras atividades econômicas).

Dado este conjunto de elementos, na década de 1990 foi singular para às políticas de conservação ambiental, sobretudo, porque o Instituto Brasileiro do Meio Ambiente e dos Recursos Naturais Renováveis - IBAMA por meio dos Núcleos Regionais de Unidades de Conservação - NURUCs desenvolve as primeiras experiências de gestão integrada e participativa nos Estados do Rio de Janeiro e Santa Catarina. Houve êxitos importantes com os NURUCs, pois estes buscavam integrar as dinâmicas ambientais, sociais e econômicas à conservação ambiental. Apesar da descontinuidade desta proposta de gestão e ordenamento da conservação, ela consubstanciou a ideia de uma política de conservação em escala regional - os Mosaicos de Áreas Protegidas, reconhecidos oficialmente em 2000 na Lei que instituiu o Sistema Nacional de Unidades de conservação - SNUC.

A intenção deste texto é demonstrar como se constituiu a ideia de mosaicos e como esta se tornou concreta na experiência empírica do Mosaico Sertão Veredas Peruaçu - MSVP, na região Norte e Noroeste de Minas Gerais e Sul da Bahia. Para isso, metodologicamente, analisamos os documentos referentes à proposta de reconhecimento do mosaico e sua inserção na legislação brasileira, bem como, o documento técnico de gestão do MSVP, o Plano de Desenvolvimento de Base Conservacionista - 
Plano DTBC, portarias de reconhecimento e os Boletins da cooperação Brasil-França sobre Áreas Protegidas ${ }^{1}$.

\section{Das UCs aos mosaicos - gestão e planejamento de conservação da natureza}

Toledo (2005), em uma crítica severa aos tradicionais mecanismos de conservação da natureza, demonstra que o fio condutor de criação de Áreas Protegidas (ou UCs para o Brasil) dá-se considerando apenas fatores biológicos, e como tal, torna-se "biotecnocracia". Segundo este autor, as áreas destinadas à conservação da natureza estão diretamente ligadas a uma concepção restrita de ciência da conservação, e como tal, sofre dos mesmos problemas daquelas, "parcelamiento y reducción de los fenómenos, abordajes especializados o monodisciplinarios". Dentro desta concepção "los problemas sólo se resuelven mediante la aplicación creciente de tecnologías.” (TOLEDO, 2005, p. 68). Analogamente, conservar a natureza torna-se um mero "isolamento" de porções da superfície terrestre (que, geralmente, inclui apenas um conjunto de espécie), sem qualquer consideração pelos condicionantes sociais, políticos, econômicos e culturais.

Este tratamento dado à conservação da natureza como mecanismo puramente biológico tem conduzido a falácias (TOLEDO, 2005). Estas dizem à respeito ao imperativo "moral" que busca e exige "completa e total" preservação da biodiversidade (isto é, as áreas de proteção integral), criando um conjunto de relações, às vezes, "intolerantes e coercitivas". A conservação por este ângulo é livre de qualquer impedimento social, econômico ou político, de tal maneira "de tal suerte que las áreas naturales protegidas deben ser mantenidas por encima de los intereses de las poblaciones locales" e sem "una conexión con las políticas de desarrollo local y regional” (TOLEDO, 2005, p. 69).

Dado estas características, as políticas de conservação mais conservadoras têm como característica serem (a) monodisciplinares, (b) monocriterial e (c) monoescalar. Em outras palavras, os mecanismos

\footnotetext{
${ }^{1}$ Trata-se de um conjunto de documentos divulgados pela Rede Mosaico sobre a cooperação técnica entre o Brasil e a França para o desenvolvimento das políticas de mosaicos no Brasil, geralmente, tratando dos avanços da cooperação, mas também dos conteúdos e resultados dos grupos de trabalho, seminários e reuniões técnicas e operacionais. Em 2009, estes boletins eram divulgados mensalmente e a partir de 2010 bimestralmente.
} 
de criação e gestão de áreas protegidas (ou UCs) observa somente um campo científico, uma escala espacial, e por isso, a conservação perde o seu caráter político e histórico e torna-se um fenômeno aespacial e a-histórico (BENSUSAN, 2006). Com isso, busca-se a "la conservación de conjuntos de especies sin considerar los elementos no vivos que integran los sistemas ecológicos o paisajísticos". Este processo leva necessariamente a não consideração do fator escala, isto é, ignoram as "las diferentes escalas en las que deben inscribirse las acciones de conservación, cada una de las cuales corresponde a una dimensión particular y concreta" (TOLEDO, 2005, p. 69).

As críticas ao modelo conservador de se estabelecer as áreas protegidas é fator dominante nos mais diversos países (DIEGUES, 2001), (BENSUSAN, 2006). É exatamente dentro destas críticas e procurando superá-las que situa as ideias do reconhecimento dos mosaicos de Áreas Protegidas (BRASIL, 2000). No capítulo IV, do artigo 26 do SNUC (Lei n 9.985/2000) diz que a existência de um mosaico ocorre a partir de um conjunto de UCs próximas, justapostas ou sobrepostas. Estas devem ser integradas formando um conjunto territorialmente delimitado.

Certos de que a conservação, tal como processada, na produção de ilhas tem eficácia limitada; dado o fato de ignorar aspectos importantes, tais como os fatores econômicos e culturais; e dada à necessidade de ampliar as escalas da própria conservação; O mosaico tem a finalidade de aperfeiçoar a gestão e as atividades nas UCs, facilitando o acesso para as pesquisas, fiscalização, monitoramento, alocação de recursos e, de certa forma, integrar e estreitar as relações com as populações abrangidas no intuito do manejo e conservação da biodiversidade.

Os mosaicos representam tanto uma medida de ordenamento do espaço e uma forma concreta de gestão dos espaços protegidos. Em outras palavras, estes representam um avanço tanto no que se refere às práticas tradicionais de gestão, quanto no que refere a complexidade necessária para implementar políticas mais efetivas para a conservação da natureza.

\section{A evolução da ideia de conservação da natureza}


Embora a proposta de reconhecimento dos mosaicos seja da primeira década de 2000 (a partir do Decreto $n^{\circ}$. 4340 de 22 de agosto de 2002 que regulamenta o SNUC), a compreensão da necessidade de expandir os instrumentos da conservação para além das UCs, é um processo histórico mais longo. A ideia da gestão integrada dos espaços de conservação e de "desenvolvimento sustentável" delineou-se entre as décadas de 1960 e 1970. O programa da Organização das Nações Unidas para a Educação, a Ciência e a Cultura - UNESCO, Homem e Biosfera (Men and biosphesre) - MaB, que deu origem as Reservas da Biosfera, tinha como princípio o zoneamento e a gestão integrada. O Programa MaB nasceu em Paris, da conferência da Biosfera em 1968, e tornou-se uma proposta efetiva a partir 1972, como um programa de cooperação voltado para as questões da interação entre o homem e o meio ambiente, com o intuito de categorizar as áreas protegidas mundiais, e compor uma rede cooperativa voltada à conservação do patrimônio natural, cultural e de promoção do desenvolvimento sustentável e da educação ambiental (BONNIN; VELUT, 2008).

Desde a sua criação como estratégia mundial de promoção e incentivo a conservação, o MaB tem como mote principal atribuir a porções representativas dos diversos ecossistemas, o Cerrado, por exemplo, o título de Reserva da Biosfera - RB. Conforme Bonnin e Velut (2008), as RBs são "um modelo de ordenamento territorial adequado para conciliar a conservação da diversidade biológica e a utilização sustentável dos recursos biológicos". Para tal objetivo "deve-se fundamentar investigações nas ciências naturais e sociais no território das reservas e sobre sua integração ao contexto geográfico". Isto exige um plano de gestão que leve em consideração a conservação e o "ordenamento do território rural" (BONNIN; VELUT, 2008, p. 3).

Tanto as RBs quanto os mosaicos, apesar de serem políticas ambientais distintas, nascem do mesmo processo - a insuficiência das UCs enquanto ilhas de conservação envolta de práticas espoliativas, cujo intuito é efetivar a conservação da biodiversidade em termos mais efetivos, mas levando em consideração o contexto geográfico (DELELIS, et al., 2010) Geralmente, as UCs são criadas em espaços em que o conflito pelo uso dos recursos naturais é latente, e quando criadas não conseguem se isolar deste processo. E, talvez, derive daí à insuficiência desta prática de modulação do espaço em contemplar o seu objetivo - a conservação da natureza. Considerar o contexto geográfico, dentre as 
dimensões espaciais, culturais e sociais e, bem como, a representação de natureza na sociedade é indispensável (TAMBELLINI, 2007).

A primeira iniciativa de superar o caráter estrito das UCs brasileiras surgiu na década de 1990 com os Núcleos Regionais de Unidades de Conservação - NURUC. Gonçalves (2000) argumenta que desde 1994 o IBAMA começou a criar mecanismos para recuperar as UCs com ações de recuperação física e com a formação do quadro funcional. Aliado a este contexto de renovação, surgiram os NURUCs cuja característica básica é ser um instrumento mais flexível e com capacidade de adequar às exigências conjunturais. Conforme o autor "os NURUCs são as instâncias regionais do sistema de gerenciamento das UCs federais e são responsáveis pela melhor operacionalização de um grupo de UCs (...)" e sua criação baseou-se "nos métodos modernos do desenvolvimento organizacional participativo" (GONÇALVES, 2000, 45).

O objetivo dos NURUCs foi o de reunir as UCs federais de uma região sob uma mesma arquitetura estrutural, isto é, o objetivo foi o de criar mecanismos regionalizados para se pensar a estrutura gerencial das UCs e os processos de conservação. E com isso, abrir espaços para se refletir sobre "o formato organizacional mais adequado ao pleno funcionamento destas e conceder maior flexibilidade e autonomia à gestão das Unidades" (GONÇALVES, 2000, 45). Os NURUCs foram criados ainda na década de 1990 no estado do Rio de Janeiro e de Santa Catarina. Embora tenha apresentado resultados concretos e mesmo o anseio de que essa ideia fosse implantada em todo território brasileiro, no início da década de 2000 o IBAMA deixou de incentivar tal prática.

Esta experiência de êxito serviu de base para a embrionária ideia de Mosaicos de Áreas Protegidas, que ganhou referência com a promulgação da Lei do SNUC em 2000. Apesar da experiência de êxito com os NRUCS, a ideia de gestão integrada e, sobretudo, o desafio de fazer isso de forma participativa serem elementos muito recentes na política ambiental brasileira. É no intuito de romper estas limitações práticas da política ambiental de gestão integrada que surgiu no início da década de 2000 a cooperação franco-brasileira para o fortalecimento e reconhecimento dos mosaicos. 


\section{A cooperação Franco-Brasileira e a ideia dos Mosaicos de Áreas Protegidas}

A cooperação franco-brasileira teve início em 2001, e teve entre os seus escopos a cooperação técnica, cujo objetivo foi o de criar mecanismos para o fortalecimento da gestão integrada e participativa dos mosaicos brasileiros. Além disso, a cooperação buscava criar os meios para o desenvolvimento territorial de base sustentável. Conforme a entrevista de Iara Vasco Ferreira, publicada no Boletim da Cooperação Brasil-França sobre Áreas Protegidas, os peritos franceses ao conhecerem o SNUC e as experiências de gestão integrada no âmbito dos NURUCs, sobretudo, o de Santa Catarina, manifestaram interesse em trabalhar com os mosaicos "por considerarem que essas unidades espaciais (os mosaicos) seriam o terreno ideal para o desenvolvimento de instrumentos de gestão e desenvolvimento sustentável em territórios mais amplos que as próprias UCs" (BCBFAP, 2010, p. 4).

Na entrevista, Iara Vasco Ferreira comenta sobre a importância desta cooperação e narra todas as experiências do processo. Para ela, os franceses contribuíram com "sua expertise em desenvolvimento territorial sustentável", com mecanismos de "articulação intermunicipal para implementação de políticas públicas no território (com foco na gestão de espaços naturais protegidos); na construção da identidade do território e no desenvolvimento da "marca-parque" (BCBFAP, 2010, p. 2-3). Nesse sentido, o instrumental técnico francês foi fundamental para se amadurecer as orientações técnicas, instrumentos e metodologias de reconhecimento dos mosaicos brasileiros.

O resultado desta cooperação foi publicado no livro "Mosaico de Áreas Protegidas: reflexões e propostas da cooperação franco-brasileira" em 2010, escrito por Delelis et al. (2010). Segundo os autores, o avanço das políticas ambientais e internacionais, bem como, a busca de formas integradoras para gestão das UCs brasileiras permitiu e aprofundou as relações de cooperação entre os dois países. O diálogo deu-se com base na experiência francesa dos Parques Naturais Regionais - PNRs e a proposta de reconhecimento e institucionalização de mosaicos no Brasil.

A cooperação envolveu visitas técnicas de treinamento e a partilha de experiências, sobretudo, observando a experiência francesa na gestão democrática e participativa dos PNRs. Do lado brasileiro, 
a parceria foi estabelecida pelo MMA por meio da Secretaria da Biodiversidade e Florestas, e o lado francês foi representado pelo Ministério dos Assuntos Exteriores e Europeus. Além disso, o Centro de Desenvolvimento Sustentável da Universidade de Brasília e a Delegação da Ação Exterior das Coletividades Territoriais foram fundamentais na construção da parceria e assistência técnica do projeto.

É preciso notar que o foco da parceria franco-brasileira tinha três escopos principais. O primeiro deles refere-se à experiência dos conselhos que dão sustentação aos PNRs, no qual participam todos os interessados na conservação da natureza-sindicatos, associações, ONGs, cooperativas, etc. Este princípio deu origem ao eixo de cooperação "governança, mobilização social e formação dos conselhos". Ainda com relação à experiência entre conservação e desenvolvimento territorial dos PNRs franceses, surgiu o segundo eixo de cooperação: “desenvolvimento territorial e criação de uma identidade territorial com bases nos recursos naturais, produtos, serviços e valorização das tradições locais". Estes dois primeiros eixos foram complementados pelo eixo "articulação de competências e de políticas de gestão" (DELELIS et al., 2010, p. 51). Estes eixos buscavam acoplar a experiência francesa em ordenamento territorial e gestão de áreas protegidas à embrionária ideia de reconhecimento de Mosaico de Áreas Protegidas no Brasil.

É interessante notar que justamente os PNRs franceses sejam modelo e o principal elemento de cooperação, e tratar-se justamente de um modelo de ordenamento e gestão da conservação. Um PRN, geralmente, é habitado e valorado do ponto de vista natural e cultural. Apesar destas características, os PNRs não são demarcados pelo Estado francês propriamente. Ao contrário, nasce da iniciativa das regiões "dentro de sua competência em matéria de ordenamento territorial", isto é, inverte-se o sentido tradicional brasileiro de criar UCs no qual primeiramente se define as áreas a serem protegidas e somente depois consulta as comunidades sobre o desejo de se criar tal UC. Nos PNRs, a sociedade convoca o Estado a criar os espaços destinados à conservação e fazem isto com o objetivo de desenvolvimento territorial. 
É sensível a semelhança e as influências dos PNRs franceses com a proposta dos mosaicos. A primeira semelhança é aquela referente à própria ideia de conservação, esta não se restringe a fatores meramente ecológicos, e as áreas protegidas ou, para sermos mais específicos, as UCs funcionam como elemento importante da engrenagem das políticas de desenvolvimento. E como tal, em ambos, a proposta é a de gestão e do ordenamento territorial por meio da conservação da natureza. Uma segunda semelhança refere-se ao valor atribuído à participação da sociedade civil na promoção da conservação da natureza e na promoção do desenvolvimento e na gestão integrada. A figura de uma sociedade civil ativa está presente na ideia dos Conselhos dos mosaicos.

A experiência de cooperação franco-brasileira se materializou no Edital do FNMA 01/2005 (edital que selecionou os mosaicos brasileiros para serem financiados pelo FNMA), no qual fica em evidência o conceito de governança territorial. A governança territorial é tratada no âmbito dos mosaicos como um conjunto de relações que "envolve a organização de modelos de gestão que integrem as distintas redes socioterritoriais", envolvendo também, em graus distintos, o "planejamento territorial baseado na conservação da biodiversidade", no reconhecimento e valorização dos fatores socioculturais e no desenvolvimento sustentável (DELELIS et al., 2010, p. 53).

Nesse sentido, a proposta de governança, presente no Edital 01 (2005) do FNMA e também no termo de cooperação franco-brasileira, envolve processos em uma escala mais ampla do que a simples gestão integrada. E como tal, surge à demanda de que a sociedade civil tenha papel ativo no reconhecimento dos mosaicos, quer seja para tomar as decisões pertinentes à conservação e quer seja para construir pactos e estruturar as linhas gerais de desenvolvimento. É interessante notar que os mecanismos de participação surgem embrionariamente no SNUC, por meio dos Conselhos Gestores, mas é regulamentado e expandido pelo Decreto nº. 4.340, de 22 de Agosto de 2002 e pelo PNAP - Plano Estratégico Nacional de Áreas Protegidas, de 2006, revelando mais uma vez a influência marcante dos modelos de gestão dos PNRs franceses na política de reconhecimento dos mosaicos brasileiros.

Enquanto projeto de gestão integrada e participativa, as motivações por detrás da proposta de um mosaico podem ser multivariadas. Estas motivações, geralmente, são os elementos que dão estrutura 
ao Plano de Desenvolvimento de Base Conservacionista - Plano DTBC. Inclui, primeiramente, a criação de mecanismos de busca por mais eficiência na gestão administrativa das UCs, por meio da gestão integrada, sobretudo, no contexto de debilidade financeira e de recursos humanos destinados para este fim no Brasil. Há também, como já destacado, a presença de mecanismos de ordenamento territorial e governança, mas o grande destaque incide sobre a possibilidade de se resolver velhos conflitos fundiários (sobretudo nas UCs de proteção integral), buscando conciliar os interesses da conservação da natureza com aqueles de populações camponesas, indígenas e quilombolas.

\section{Conservação da natureza e desenvolvimento territorial de base conservacionista}

Dois fatos são emblemáticos quando se coloca em questão a proposta dos Mosaicos de Áreas Protegidas em contemplar a conservação e o desenvolvimento. Primeiro é a afirmação de que estes devem contribuir com as propostas de desenvolvimento regional sustentável. É preciso dizer que a ideia de desenvolvimento (não importa os adjetivos que se acrescentem a ele) tem como premissa a exploração da natureza, tornando-a fonte do crescimento econômico e do bem estar material de parcela da população. Além disso, o desenvolvimento tal como tem sido praticado (conforme aponta Bové (2009) e Waren (2016)) aciona a ideia de produção, de consumo, nos qual o "crescimento econômico e o ‘desenvolvimento' são quantificados e medidos de acordo com os níveis gerais de industrialização e produtividade, mas também pelos níveis de consumo (...) cada vez mais altos de energia e da natureza" (WAREN, 2016, p. 13). É implícito à ideia de desenvolvimento que a natureza nada mais é do que um domínio de exploração

Ao refletir sobre as implicações das políticas de desenvolvimento sobre as sociedades ocidentais, Bové (2009, p. 20) lança uma questão inquietante: "o que era gratuito passou a ser pago". Em outras palavras, a principal consequência do mito do progresso e do desenvolvimento é a "supermercadilização" de todas as coisas, da natureza à cultura, da economia às consciências, da técnica à ciência, etc. Daí advém à premissa “desfazer o desenvolvimento para refazer o mundo". 
Quando o termo desenvolvimento é colocado em questão desperta todos os tipos de paixões. Uns acreditam que a rota pode ser mudada, um desenvolvimento alternativo, sustentável, duradouro, etc., pode modificar as relações que a sociedade estabelece entre a natureza e a economia. Outros acreditam que o desenvolvimento "é um mito", ou de modo ainda mais enfático apontam "que essa lógica do desenvolvimento é totalmente suicida. Ela recusa a olhar em volta, prossegue sem ter noção de seus atos" (BOVÉ, 2009, p. 20). Parece que a primeira perspectiva prevalece nos ideólogos do desenvolvimento territorial de base conservacionista.

Um segundo ponto chama a atenção para os Mosaicos, o simples ato de demarcar "pedaços" do espaço geográfico com finalidade de salvaguardar parte das riquezas bióticas e abióticas de um ambiente qualquer é muito significativo. Isto revela uma dinâmica singular de controle da natureza, que busca assegurar um mínimo das riquezas ambientais diante de dinâmicas produtivas cada vez mais espoliantes (dinâmicas estas originárias das "políticas de desenvolvimento"). Revela o fato que a própria natureza se tornou uma "raridade", um bem em disputa, isto é, a natureza deixa de ser um mero fator produtivo e entra no campo dos valores.

Nesse sentido, a ideia subjacente aos mosaicos de integrar os diferentes espaços da conservação de modo a assegurar melhores mecanismos de manejo e gestão é importante. Primeiro, porque reconhece a conservação como prática social, isto é, como inserida dentro das dinâmicas, sociais, culturais e econômicas. E dada esta característica deve ser pensada como um processo político de ordenamento do território. Segundo, a conservação que, às vezes, contribui para precarização territorial e econômica de comunidades inteiras, deve ser repensada, embora se proponha para isso a ideia "do desenvolvimento territorial de base conservacionista”.

Resta antes de prosseguirmos, indagar: qual é o sentido que "o desenvolvimento" assume na proposta dos Mosaicos de Áreas Protegidas, mais especificamente, de que maneira a questão do desenvolvimento é enfrentada pelo Plano de Desenvolvimento Territorial de Base Conservacionista do Mosaico Sertão Veredas Peruaçu - Plano DTBC do MSVP? E como se estabelece a relação entre a conservação e o desenvolvimento? Existe uma longa história por detrás do conceito de 
“desenvolvimento territorial de base conservacionista”, mas a intenção aqui é resumir suas principais premissas para que possamos analisar a lógica dos conflitos que se desenvolve no seio do MSVP.

Dois documentos são importantes para a estruturação do conceito de desenvolvimento territorial de base conservacionista. O texto de Ronaldo Weigand Junior (2005) "Que es desarrollo territorial con base conservacionista" e o "Edital 01/2005 do Fundo Nacional de Meio Ambiente/Ministério do Meio Ambiente". A partir da leitura e análise destes documentos fica claro uma premissa básica: desenvolvimento e a conservação da natureza não são atividades díspares ou conflitantes, ao contrário, podem ser complementares. Isto quer dizer que os territórios utilizados pela conservação podem tornar-se elementos essenciais na geração de "produtos e serviços para atividades que contribuam para a geração de uma economia com base conservacionista" (FNMA/MMA, 2005, p. 7).

Nesse sentido, o conceito de desenvolvimento territorial de base conservacionista pretende "estabelecer formas de associação entre desenvolvimento e conservação, estabelecendo e fortalecendo cadeias produtivo-econômicas que têm, como base, os produtos e serviços gerados pelas atividades conservacionistas". Tais atividades econômicas devem articular às "iniciativas promotoras da gestão ecossistêmica do território, com o intuito de compatibilizar a conservação da biodiversidade, o desenvolvimento de atividades econômicas e a melhoria da qualidade de vida das populações" (FNMA/MMA, 2005, p. 7).

A primeira questão que chama atenção nestas passagens é a correlação entre desenvolvimento e a melhoria da qualidade de vida. Isto é, a relação de causa e efeito entre o desenvolvimento (neste caso territorial de base conservacionista) e a renda. O desenvolvimento então é tratado de forma mais redutível possível: aciona noções instrumentais como evolução, mudanças e, sobretudo, a de crescimento, ou simplesmente como acréscimo de renda. Embora os adjetivos "territorial" e “conservacionista" mude o tom conceitual, na prática os desejos permanecem o mesmo, o crescimento econômico deve ser a principal estratégia de desenvolvimento. 
Se no Edital esta correlação não é diretamente textual, Weigand Junior não deixa espaços para dúvidas. Para ele, "o conceito de desenvolvimento envolve a geração de renda e melhoria da qualidade de vida, a geração de riquezas e, ao esmo tempo, sua distribuição justa e a eliminação (...) da pobreza" (WEIGAND JUNIOR, 2005, p. 2). Segundo o autor, todo modelo desenvolvimento tem uma base concreta de realização, mas isto geralmente não fica expresso. Assim, por exemplo, a indústria, a agricultura e o turismo podem ser bases para o desenvolvimento. Mas, no caso da proposta dos Mosaicos, o desenvolvimento deve pautar-se pela conservação da biodiversidade e dos processos ecológicos.

Weigand (2005, p.2) esclarece a correlação entre a conservação e o desenvolvimento quando lamenta que “(...) a conservação da natureza é frequentemente esquecida como potencial gerador de uma base econômica para o desenvolvimento do território". Está implícito no Edital e em Weigand (2005) duas tentativas de redimensionar os conceitos. No lugar da conservação como espaço estanque e prática antagônica ao desenvolvimento, passa-se a considerá-la como elemento de dinamização econômica e territorial. No lugar do desenvolvimento enquanto atividade espoliativa da natureza e dos homens consideram-no como meio para se atingir a conservação da biodiversidade e dos processos ecológicos.

A segunda questão importante das passagens citadas refere-se à temática das "cadeias produtivas e econômicas" que podem contribuir para o desenvolvimento territorial de base conservacionista. 0 Edital não deixa claro quais as atividades podem ser consideradas "conservacionistas", mas o texto de Weigand ao se indagar "quais são as bases para o desenvolvimento" esclarece e complementa estes pontos. Para ele, a conservação gera produtos e serviços que se bem geridos podem contribuir significantemente para o desenvolvimento. Para isto, é preciso pensar as UCs (de uso sustentável e proteção integral) dentro de uma visão estratégica que limita as práticas de desenvolvimento mais espoliativas, como por exemplo, mineração, atividades industriais e agropecuárias intensivas; e potencializam as atividades sustentáveis, tal como o ecoturismo, extrativismo, etc.

O desenvolvimento territorial de base conservacionista tem como "base" produtos e serviços, tais como: (a) conservação da biodiversidade genética de espécies; (b) proteção dos recursos hídricos; (c) 
manutenção dos ecossistemas que abrigam espécies de valor comercial; (d) manutenção da beleza cênica dos lugares; (e) sequestro de carbono; (f) atividades que contribuem para a sustentabilidade dos meios de vida e conhecimentos tradicionais. Aparecem entre estas estratégias desde propostas para bioprospecção, identificação de princípios ativos, manipulação genética, pesquisa científica, até alternativas como o turismo sustentável, extrativismo, comércio de carbono, etc. Conforme Weigand Junior (2005, p. 3[Grifos meus]), os desafios são claros. Primeiro, "porque temos que gerar renda a partir de atividades normalmente vistas como gastos", segundo, porque "estas devem trazer remuneração e renda para as populações do território (...) com competividade, se comparada a outras bases, como a pecuária". Cada proposta de reconhecimento dos mosaicos absorve estas indicações conforme as "potencialidades" locais.

O desenvolvimento territorial de base conservacionista conforme proposto pelo Edital 01/2005 e Weigand Junior (2005) carrega consigo velhos e novos problemas. Em primeiro lugar, está implícita a ideia de linearidade, isto é, um antes (subdesenvolvido) e um depois, o desejado (desenvolvido), há a dualidade desenvolvido/subdesenvolvido, avançado/atrasado. Conforme mostra Acosta (2015) estes princípios vêm historicamente mobilizando nações e povos em todos os lugares que fazem todos os sacrifícios para adaptar-se, desenvolver-se. Ao propor velhos temas com "ares" de novidades, não se questionam se há outros modos de vida alternativos e outros mecanismos para se engajar populações e conservação.

O sobrenome "conservacionista" não aboliu todo o conteúdo ideológico do desenvolvimento. No plano mais geral, conforme aponta Acosta (2015) o revisionismo tem o intuito de salvar e reoperacionlizar o ideal fracassado. Acrescentam-se adjetivos, mas a ideia de base continua: aumento de rendas e consumo material. Pouco se questiona que isso significa a transferência de riquezas, a espoliação de modos de vida, etc.

Mosaico Sertão Veredas Peruaçu - Norte de Minas Gerais, Nordeste de Goiás e Sul da Bahia 
A ideia do MSVP começou a se desenhar em 2005, quando a Funatura participou do Edital 01/2005 do Ministério do Meio Ambiente - MMA e do Fundo Nacional do Meio Ambiente - FNMA, Edital que selecionou os projetos de mosaicos para financiamento. Aprovado por este Edital, o projeto do MSVP entrou em execução em 2006 e foi reconhecido oficialmente em 2009, por meio da Portaria do MMA de $\mathrm{n}^{\circ} 128$, de 24 de Abril. Este mosaico tem uma área total de 1.500.000 hectares. É formado por quatorze UCs administradas pelo Instituto Mineiro de Florestas - IEF e Instituto Chico Mendes de Conservação da Biodiversidade - ICMBIO. Entre as quatorze UCs, há quatro Reserva Particular do Patrimônio Natural - RPPNs sob a gestão de empresas e fazendeiros, quatro Áreas de Proteção Ambiental - APAs, uma Reserva de Desenvolvimento Sustentável - RDS e cinco unidades de proteção integral (dois Parques Nacionais e Três parques estaduais. O território é constituído por onze municípios, 10 no estado de Minas Gerais, 1 município goiano e outro no estado da Bahia. Conforme podemos observar na Figura 1.

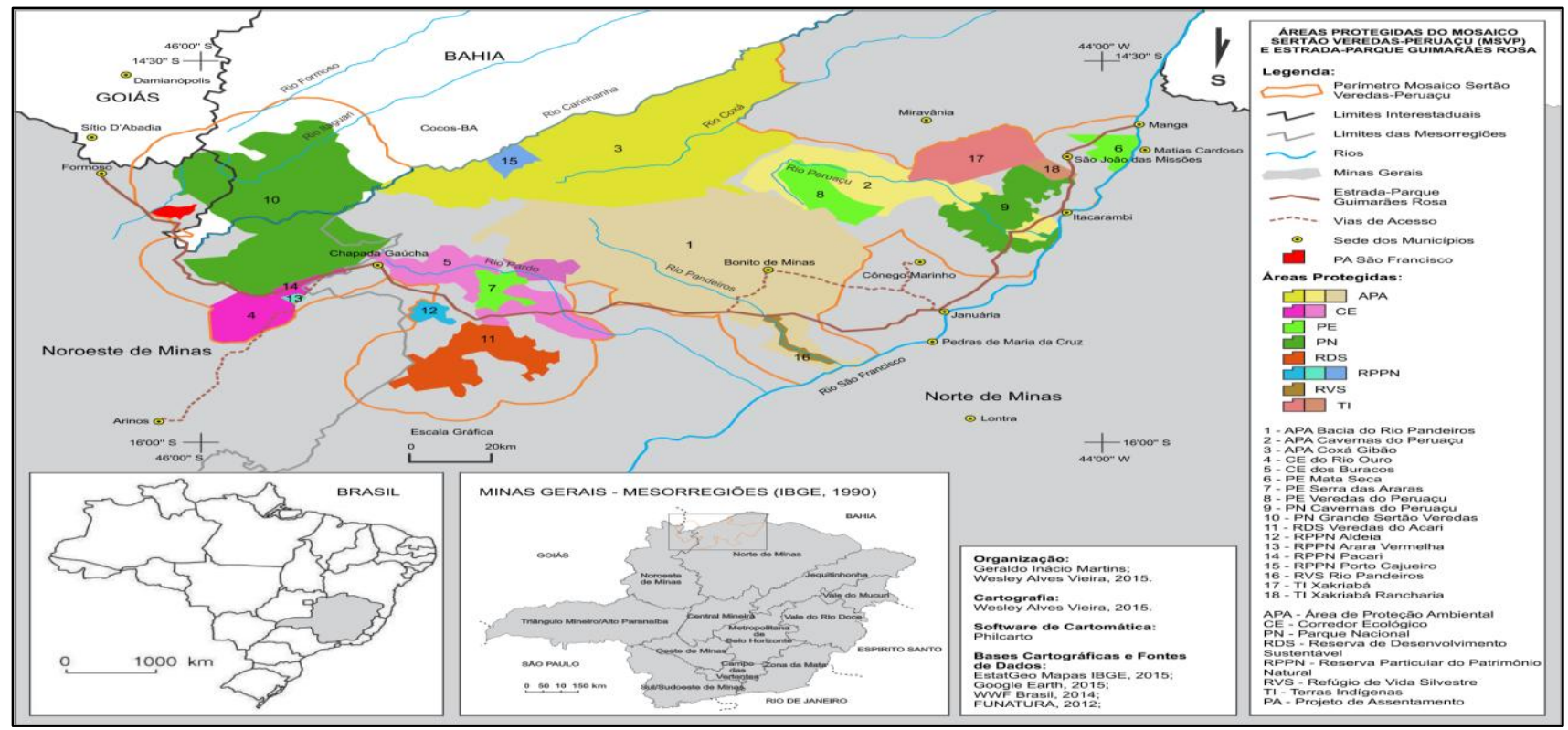

Figura 1. Território do Mosaico Sertão Veredas-Peruaçu - Norte de Minas Gerais, Sul da Bahia e Nordeste de Goiás. Fonte: ANA, FUNAI, FUNATURA, IBGE, IEF-MG. Org.: Funatura (2012).

A partir da figura 1 pode-se observar que o mosaico tem um importante recorte espacial. É preciso ponderar ainda que na sua área de abrangência há uma terra indígena, a Reserva dos Xacriabás, um território quilombola, o Quilombo São Félix, comunidades locais camponesas e o Projeto de Assentamento - PA São Francisco (PA criado para receber camponeses remanejados Parque Nacional 
Grande Sertão Veredas - PARNA GSV). A entrada de Terras Indígenas na área do mosaico vem no intuito de criar "arranjos que possibilitem e viabilizem a participação efetiva dos povos indígenas (...) na consulta e gestão" dos mosaicos, conforme o documento de Recomendações para o Reconhecimento e Implementação de Mosaico e Áreas Protegidas (DELELIS et al., 2010, p. 34).

Outro ponto importante referente aos mosaicos de forma geral, e ao MSVP em específico, é a possibilidade de tratar de outro modo uma das questões mais sensíveis das políticas de conservação ambiental, a presença de comunidades no interior de áreas de conservação. A possibilidade da criação de áreas de conservação de uso sustentável, legalmente introduzida pelo SNUC, abriu um interstício no conservadorismo das políticas de conservação no que se refere a este tema. A proposta do mosaico de integrar as comunidades locais e também a sociodiversidade amplia o escopo de debate. E a ideia de que a conservação só pode ser realizada sem presença humana começa a ser minada e no lugar surge os primeiros indícios do reconhecimento do papel destas comunidades na manutenção da diversidade biótica e abiótica das áreas por elas apropriadas. E com a proposta de incluir as UCs, como instrumentos de desenvolvimento regional, amplia-se ainda mais esta discussão.

E, por fim, é preciso destacar os objetivos do MSVP:

Promover o desenvolvimento da região em bases sustentáveis e integrado ao manejo das unidades de conservação. (...) a gestão integrada das unidades de conservação e demais áreas protegidas (...). Promover a implementação de práticas voltadas para o extrativismo vegetal (...) compatíveis com a proteção das unidades de conservação; Promover o desenvolvimento do turismo ecocultural sustentável na região(...) (FUNATURA, 2008, p. 7).

Estes objetivos foram desdobramentos dos principais eixos do plano de desenvolvimento do MSVP Gestão Integrada, Extrativismo e Turismo Ecocultural. Estes eixos fundamentam o objetivo geral do mosaico, o desenvolvimento regional de base conservacionista. Trata-se, portanto, da premissa do envolvimento de vários sujeitos sociais interessados e/ou atingidos pela conservação da natureza na construção de um pacto, cujo objetivo final é a proteção e a conservação da natureza.

\section{Gestão integrada e desenvolvimento de base conservacionista no MSVP}


A principal característica do Plano DTBC elaborado pela Funatura junto com o Conselho do mosaico é a visão ecossistêmica sobre a biorregião do MSVP. Embora, o principal objetivo seja o de encontrar estratégias para se pensar a conservação da natureza para além das UCs, isto é, pensar a conservação como parte integrante da biorregião, outros elementos aparecem de forma ímpar. Isto pode ser observado no objetivo geral do Plano DTBC que é o de "promover o desenvolvimento da região em bases sustentáveis e integrado ao manejo das Unidades de Conservação e demais áreas protegidas do Mosaico Sertão Veredas - Peruaçu" (SANTO, 2012, s/p).

Além da gestão integrada, o Plano DTBC propõem outras atividades ligadas à conservação e ao uso sustentável, sobretudo, aquelas ligadas ao turismo ecocultural (segundo eixo de desenvolvimento) e extrativismo de bases sustentáveis (terceiro eixo de desenvolvimento). Com a aposto no turismo buscou-se "atrair turistas interessados em comprar os serviços que permitam contemplar, conviver e usufruir, aprender e intercambiar com os patrimônios culturais e naturais" da biorregião do MSVP (FUNATURA, 2008, p. 31).

A aposta no extrativismo em bases sustentáveis parte do princípio que tal atividade pode contribuir com a conservação do Cerrado, mas também pode contribuir com o desenvolvimento em bases conservacionistas. Além da importância biológica, quando se propõem o aproveitamento dos serviços ambientais do Cerrado, propõem-se também a valorização de elementos culturais típicos da biorregião. Isto porque estas atividades fazem parte das gramáticas sociais das comunidades regionais, como bem reconhece um dos relatórios da Funatura, quando observa que "praticar o aproveitamento de produtos do cerrado (...) não é algo tão distante da prática das populações do território do mosaico" (FUNATURA, 2008, p. 14).

No entanto, o principal eixo de desenvolvimento do Plano DTBC do MSVP é a gestão integrada. Segundo Manuela Tambellini (2007, p.80), subjaz a ideia de gestão integrada uma mudança de paradigmas no qual as Áreas Protegidas em geral (e as UCs de forma mais específica) até então entendidas como "ilhas", "espaços autossuficientes tanto administrativas quanto ecologicamentente, sem gestão territorial integrada", passam a ser vistas como parte de um sistema maior. 
Tambellini (2007, p. 82) defende a ideia de que um mosaico "deve ser entendido como um organismo vivo, no qual suas partes dependem uma das outras para viver". Integrar estas diversas partes que, teoricamente, parecem separadas é o grande desafio da gestão integrada. A gestão, enquanto condução de uma organização a uma meta específica, considerando as normas e as condições para isto, contribui para se pensar a complexidade dos mosaicos. Nesse sentido, na "gestão integrada, esta condução deve ser feita de maneira compartilhada, onde suas metas e objetivos levam a uma visão de futuro comum". Evidentemente que para efetivar tal processo é preciso notar os possíveis conflitos, interesses e, sobretudo, as dificuldades de relações entre as instituições e as pessoas. Gestão integrada tem relação direta com posturas administrativas abertas ao diálogo, com a resolução de conflitos, enfim, tem a ver com pensar os mosaicos enquanto totalidade.

Conforme o Decreto $\mathrm{n}^{0}$ 4.340/2002, o modelo de gestão integrada subjacente aos mosaicos visa compatibilizar, integrar e aperfeiçoar as atividades empreendidas em cada UC, considerando, em especial, os diversos usos nas fronteiras entre as unidades, o acesso às unidades. Além disso, a gestão integrada deve monitorar e avaliar os planos de manejo, pensar a respeito do alocamento de recursos referente a licenciamentos ambiental de impactos significativos. Outro objetivo subjacente à ideia de gestão integrada é o estreitamento das relações das comunidades do mosaico.

Quando se trata de gestão integrada, a figura do conselho é primordial. No que se refere ao Conselho do MSVP, é nele que todos os processos são pensados, isto também inclui aqueles elementos ligados às alternativas de desenvolvimento voltadas às comunidades locais - extrativismo e turismo ecocultural. Em termos gerais, a principal função de um Conselho Gestor de um Mosaico é criar as condições para que se efetive a gestão integrada. Isto é, o conselho deve funcionar como o principal espaço de diálogo no qual se debate os conflitos, promove reflexões relativas à conservação, sobre as interdições e as possibilidades de uso da natureza. Além destas questões mais funcionais, o conselho deve ser o ponto de mediação entre os diversos gestores das UCs que compõem o mosaico, mas também o local no qual os gestores mantêm diálogo com as comunidades. Para nós, em gesto de antecipação, ao considerar o exemplo do MSVP, o conselho é mais do que um instrumento jurídico normativo, é o lugar do conflito e do consenso e, sobretudo, o lugar de integração e de construção de estratégias para se pensar os 
problemas regionais ligados à conservação da natureza, as identidades biorregionais e também estratégias de desenvolvimento.

Boa parte das discussões sobre mosaicos e seus conselhos remetem aquelas funções determinadas normativamente, mas é preciso notar que os Conselhos precisam ter um escopo de ação diferenciado. Não é somente a questão da conservação ou estratégias da conservação que está em jogo, é preciso ter a ciência que os mosaicos devem integrar as atividades econômicas regionais e, ao mesmo tempo, atuar como indutores de desenvolvimento de base conservacionista. Além destas questões, outras como os conflitos entre as normas impostas pela conservação ambiental e as comunidades que vivem no interior ou no entorno das UCs também é um espaço no qual os conselhos exercem papel importante.

É por ser este espaço dialógico que a participação das comunidades locais, das entidades de classe, ONGs e órgãos ambientalistas tornam-se a principal matéria-prima do trabalho. Conforme o Regimento Interno do Conselho Consultivo do Mosaico Sertão Veredas - Peruaçu - RICCMSVP, o Conselho do MSVP tem "por finalidade contribuir para a efetiva implantação e gestão integrada do mosaico", além de atuar como "instância de gestão integrada das Unidades de Conservação" e contribuir "para a preservação e conservação dos recursos naturais, bem como para o desenvolvimento sustentável deste território" (FUNATURA, 2008, p.1).

A existência legal do Conselho não é precondição para que este atue de forma efetiva. Esta condição ganha complexidade, considerando que os Conselhos legalmente assegurados pelo o SNUC e o decreto de regulamentação são consultivo, esta característica diminui a escala de ação e de intervenção prática. Isto requer ainda mais esforços das instituições que formam a arquitetura dos Conselhos, dada à limitação jurídica e dada a limitação do escopo de ação concreta. Apesar disso, sobretudo, quando observamos o caso concreto do Conselho do MSVP, notamos que a construção do pacto em torno de instituições da sociedade civil e daquelas ligadas mais propriamente ao Estado contribui em muito para diminuir estas restrições. 
Além de um Conselho Gestor ativo, a proposta de gestão integrada tem outras facetas importantes, tal como sistematizado no Quadro 1, onde são apresentados os focos principais da gestão integrada e os objetivos esperados. Neste quadro detalhamos as linhas gerais da proposta de gestão integrada do MSVP. Alguns programas, por exemplo, a operacionalização do Conselho Consultivo, que plenamente e tem a sua própria dinâmica. Há, ainda, entre as metas da gestão integrada, programas voltados a maior eficiência da fiscalização das UCs e eficiência no combate a incêndios. Evidentemente, a avaliação da efetividade destes eixos torna-se difícil, sobretudo, pela falta de dados anteriores ao reconhecimento do mosaico.

\begin{tabular}{|c|c|c|c|}
\hline Estratégia & Metas & $\begin{array}{c}\text { Instituição } \\
\text { responsável }\end{array}$ & Objetivos \\
\hline \multirow{5}{*}{$\begin{array}{l}\text { Gestão } \\
\text { integrada }\end{array}$} & $\begin{array}{l}\text { Programa de Fiscalização } \\
\text { Integrada. }\end{array}$ & \multirow{5}{*}{ Funatura/IEF } & $\begin{array}{l}\text { Visa proporcionar ao MSVP um conjunto } \\
\text { integrado de ações integradas para } \\
\text { monitorar as UCs biorregionais. }\end{array}$ \\
\hline & $\begin{array}{l}\text { Programa Integrado de } \\
\text { Prevenção e Combate a } \\
\text { Incêndios Florestais. }\end{array}$ & & $\begin{array}{l}\text { Visa à execução de um conjunto de } \\
\text { atividades capazes de prevenir e combater } \\
\text { focos de incêndios. }\end{array}$ \\
\hline & $\begin{array}{l}\text { Programa Integrado de } \\
\text { Pesquisa Científica. }\end{array}$ & & $\begin{array}{l}\text { Difundir as pesquisas realizadas na } \\
\text { biorregião do mosaico, sobretudo, aquelas } \\
\text { com foco em Áreas Protegidas. }\end{array}$ \\
\hline & $\begin{array}{l}\text { Programa de Levantamento } \\
\text { da Situação Fundiária das } \\
\text { UCs. }\end{array}$ & & $\begin{array}{l}\text { Conhecer de maneira detalha a situação } \\
\text { fundiária de cada UC do MSVP. }\end{array}$ \\
\hline & $\begin{array}{l}\text { Programa de } \\
\text { Operacionalização do } \\
\text { Conselho do Mosaico. }\end{array}$ & & $\begin{array}{l}\text { Visa o fortalecimento do Conselho } \\
\text { Consultivo do MSVP. }\end{array}$ \\
\hline
\end{tabular}

Quadro1 Ações e metas da gestão integrada no MSVP. Fonte: Plano DTBC - Funatura (2008). Org: MARTINS, G.I., 2014.

A primeira meta descrita no Plano DTBC é o programa de fiscalização integrada do MSVP. Esta meta visa potencializar os esforços a fim de encontrar uma solução viável ambiental e economicamente para os principais desafios no que refere à gestão e consolidação das UCs, desafios identificados durante as pesquisas de campo de elaboração do Plano DTBC. Entre estes desafios estão àqueles ligados às "atividades impactantes no entorno das Unidades de Proteção integral e de forma generalizada nas de uso sustentável" (FUNATURA, 2008, p. 41). A rigor, os principais problemas das UCs referem-se à conversão das áreas de vegetação do Cerrado para monocultivos de grãos, bovinocultura e para produção de capim - atividades essencialmente ligadas ao agronegócio. Um segundo conjunto de 
problemas refere-se à exploração do Cerrado para a produção de carvão, na maioria das vezes, sem qualquer licenciamento ambiental. E, por fim, estão os problemas das queimadas na renovação de pastagens e o tráfico de animais silvestres.

Boa parte dos problemas descritos, além do fator ambiental, inviabiliza também o êxito dos demais eixos de desenvolvimento do mosaico, isto é, o aproveitamento da biodiversidade para o turismo ecocultural e para o extrativismo. Estes desafios referem-se diretamente aos conflitos entre as diversas lógicas e formas de apropriação da natureza. Este contexto é complexificado, se considerarmos que boa parte das UCs tem infraestrutura insuficiente, número insuficiente de funcionários, ocupações irregulares, etc. A maioria se quer tem um plano de gestão e desenvolvimento. Assim, temos de um lado o uso expropriante da natureza, e de outro, aqueles espaços destinados a proteger e conservar a natureza precarizados. O resultado disso é que boa parte da biodiversidade utilizada amplamente de várias formas (remédios, alimentos, corantes, aromas, cosméticos, utilitários etc.) pelas comunidades locais fica em risco. Portanto, esta primeira meta coloca a necessidade iminente de encontrar soluções viáveis econômica e ambientalmente para tais problemas.

Complementar a esta primeira meta, um dos desafios da gestão integrada, conforme o Plano DTBC, é um programa integrado de prevenção e combate a incêndios. A proposta subjacente a este programa é o "envolvimento de todas as comunidades, instituições públicas, órgãos de assistência técnica, associações da sociedade civil (...) em um conjunto de esforços para redução das queimadas" (FUNATURA, 2008, p. 54). Apesar do caráter ambicioso desta proposta e de sua efetividade, teoricamente falando, ela tem desafios complexos. O primeiro deles é a relação quase sempre conflituosa entre gestores e comunidades locais, entre comunidades e as imposições da legislação ambiental. Durante as nossas pesquisas de campo, em 2010, com os camponeses remanejados do PARNA GSV, notamos uma negatividade atribuída às UCs. O fogo nas UCs é sinônimo de protesto a precarização dos modos de vida das comunidades, sobretudo, pelas restrições impostas pela conservação. 
Outro programa da gestão integrada do MSVP é o incentivo a pesquisas científicas nas UCs do mosaico. Tal meta visa apoiar pesquisadores "interessados em trabalhos científicos na região do mosaico e a realização de encontros com a presença de especialistas em espécies ameaçadas" (FUNATURA, 2008, p. 55). Certamente, este eixo é um dos mais ambiciosos, mas também um dos mais necessários. A biorregião do MSVP conta com ambientes e paisagens muito diversas, a expansão do agronegócio, o tráfico de animais, etc., coloca em risco toda esta riqueza. É preciso conhecê-la profundamente, sobretudo, para que os planos de manejo de cada UC possam focar seus objetivos em proteger e conservar estes ambientes e espécies.

Para além desta função mais geral das pesquisas científicas na biorregião do MSVP, elas também podem ter uma função mais pragmática. A maioria das UCs não tem se quer um plano de manejo. Estas podem contribuir na formação de um banco de dados para subsidiar a elaboração de tais planos. Apesar desta dupla importância, é preciso ter ciência de que estas pesquisas envolvendo a biodiversidade devem também incluir o conhecimento das comunidades locais a respeito da riqueza biótica e abiótica da biorregião. Além disso, é preciso colocar em análise o lado geopolítico da biodiversidade.

Complementar a todos estes programas da gestão integrada, situa-se aquele que pretende realizar levantamento da situação fundiária das UCs do MSVP. O objetivo é conhecer "de maneira detalhada, a situação fundiária" de cada UC, fazendo georreferenciações e revisando aquelas existentes (FUNATURA, 2008, p. 56). Evidentemente que o levantamento da situação fundiária é necessário para a consolidação das UCs. É necessário para efetivar o programa de fiscalização integrada e também parte da solução dos problemas das queimadas.

Mas, nele também observamos um distanciamento entre os objetivos propostos e os caminhos apontados para atingi-los. O exemplo das UCs, no qual este processo de levantamento fundiário aconteceu, como o PARNA GSV, ajuda-nos a analisar esta questão. Nesta UC o principal problema encontrado foi aquele da titularidade formal (o proprietário jurídico) e o proprietário de direito (o posseiro). Boa parte das propriedades existentes juridicamente não existia de fato, isto é, uma fazenda 
apesar de existir documentalmente, empiricamente era formada por uma gama variada de famílias camponesas ocupantes seculares de tais territórios, mas sem qualquer tipo de documentação. A cartografia do PARNA GSV não conseguiu captar toda esta complexidade.

Nesse sentido, mais do que a situação fundiária, isto é, o levantamento dos tipos de propriedades e proprietários, quando se observa a complexidade de ocupações da biorregião do MSVP, a questão latente que se coloca é os tipos de uso das terras, tendo em vista que a relação dono e usuário nem sempre se coadunam. Portanto, mais uma vez, a questão que se revela é a falta de um olhar histórico sobre a biorregião, olhar sobre a história da formação territorial e dos sujeitos desta formação. Este programa da gestão integrada é importante, mas ele deve ser complementado por estudos históricos de uso e ocupação da terra. Estas questões mais elementares não são contempladas pelo Plano DTBC, apesar de reconhecer a importância das comunidades locais no planejamento da conservação e, sobretudo, em sua consolidação, não toca em temas essenciais como as metas de garantia de justiça ambiental, a garantia da terra de trabalho, por exemplo.

Além destes programas e metas da gestão integrada, há outros objetivos, tais como a "capacitação de gestores e conselheiros visando (...), a participação efetiva e qualificada dos diversos atores que agem no território e que tenham assento do Conselho", além da divulgação "das ações desenvolvidas no território do Mosaico que estejam em consonância com o Plano de DTBC" (SANTO, 2012, p. 25). Estes objetivos estão contemplados no Conselho Consultivo do Mosaico do MSVP, formado por instituições públicas e da sociedade civil, e no Jornal do Mosaico, principal instrumento de divulgação das ações empreendidas pelo conselho no âmbito do MSVP.

A principal estratégia apontada é disseminar entre as comunidades do MSVP, os objetivos do Plano DTBC, sobretudo, demonstrando o efeito deste nas "atividades econômicas tradicionalmente praticadas". A rigor, estas estratégias podem contribuir com "redução gradativa de atividades potencialmente degradadoras do meio ambiente, como a pecuária e os monocultivos de exportação" (FUNATURA, 2008, 41). Apesar de tratar estes processos como linha mestra da gestão integrada, em todo o texto não fica claro os meios técnicos e econômicos para tal fim. 
Em síntese, parece que as ações empreendidas no âmbito do Plano DTBC e no âmbito do Conselho Consultivo são isoladas dos demais processos políticos e econômicos desenvolvidos na biorregião. Este isolamento pode ser notado inclusive na "Avaliação de Efetividade de Mosaicos de Unidades de Conservação", elaborada pela WWF (COSTA; HERRMANN, 2015). Alguns indicadores apresentados foram considerados não efetivos, como, por exemplo, a atuação do Conselho nos processos de licenciamento ambiental da biorregião, na alocação dos recursos advindos de compensação ambiental e se os objetivos do mosaico são considerados em programas e políticas de desenvolvimento para biorregião.

Conforme os dados apresentados por Costa e Herrmann (2015), o eixo de gestão integrada e participativa é o menos consolidado no MSVP, e vários componentes políticos e institucionais concorrem para este fato. Primeiramente, a proposta de gestão integrada pressupõe distribuição de poder, decisões que, outrora, eram tomadas de forma isolada, agora devem ser concebidas de forma democrática e participativa. Com efeito, as resistências a este processo emergem, a distribuição de poder pressupõe aprofundamento da cultura democrática, e considerando o contexto autoritário que as UCs são criadas e, geralmente, geridas, o desafio neste sentido é amplo. Além destas questões de ordem política, há também as de ordem institucionais, UCs obedecem às esferas distintas de poder (Estadual e Federal), mas também órgãos gestores distintos (IEF- Instituto Estadual de Florestas, ICMBio, reservas particulares). Construir um sistema de cooperação entre poderes e instituições demanda alta capacidade de negociação, desafio colocado para o Conselho e Gestores do MSVP.

Além disso, concorre para "baixa efetividade" o fato de o mosaico, as reuniões, a formação das equipes de trabalho acaba sendo vista "por alguns gestores como mais uma tarefa a ser executada na agenda já sobrecarregada pela falta de pessoal” (COSTA; HERRMANN, 2015, p.36). Ao contrário do que acontece com a gestão integrada, que encontra dificuldades para se concretizar, as ações voltadas à proteção e à biodiversidade são mais efetivas. Isto se deve, entre outras coisas, "aos trabalhos desenvolvidos por uma instituição de pesquisa integrante do Conselho [Biotrópicos]" que tem contribuído para as pesquisas com o levantamento e catalogação de anfíbios e mamíferos. 
Um segundo elemento crítico encontrado durante a avaliação da efetividade do eixo de desenvolvimento do mosaico refere-se à falta da "presença e os objetivos do Mosaico (...) em programas e políticas de desenvolvimento projetadas para o território" (COSTA; HERRMANN, 2015, p.35). Em outras palavras, embora o MSVP seja um mecanismo territorial de conservação e desenvolvimento, boa parte dos municípios da biorregião, exceto o de Chapada Gaúcha, desenvolve seus planos de desenvolvimento sem qualquer menção às estratégias de desenvolvimento propostas pelo Plano DTBC. Isso acontece porque, geralmente, as propostas de desenvolvimento do MSVP não interessam aos gestores municipais. Esta falta de interesse, porém, é elucidativa de uma questão importante: o papel que se atribui às políticas que buscam integrar desenvolvimento e conservação.

Em resumo, as análises do Relatório da WWF apontam que “(...) a oportunidade de agregar pessoas com poder de influir no território e de trazer recursos e projetos contribui para o sucesso do Mosaico". Os autores argumentam que o modelo de gestão integrada "facilitou a articulação entre pessoas e instituições" (COSTA; HERRMANN, 2015, p.41). As ações empreendidas ao longo dos últimos anos contribuem em muitas dimensões para a percepção ambiental, política e econômica da biorregião do MSVP.

Por fim, é preciso considerar que a gestão integrada e participativa é uma das forças motrizes da política de mosaicos. Mas é preciso pensar a participação para além das figuras dos Conselhos Consultivos, tal como o do MSVP. Isto é, uma participação passiva, de fornecimento de informações ou de consulta, portanto, mais instrumental do que prática. A verdadeira participação requerida para consolidar e aprofundar os mosaicos de forma geral, e o MSVP em específico, passa pelo processo automobilização, no qual as comunidades tomam a inciativa para mudar a forma, as regras e os modelos de gestão e conservação. Esta participação automobilizadora independe da ação de agentes externos, ONG, por exemplo, pois é pautada na autonomia, na distribuição de poder e no questionamento das estruturas existentes.

\section{CONSIDERAÇÕES FINAIS}


Neste trabalho defendemos a ideia de historicidade subjacente à ideia de gestão integrada, bem como, as constantes críticas aos modelos de conservação stricto sensu. É destas críticas que surgem algumas estratégias que buscam pensar a conservação ambiental dentro de um quadro mais amplo, o exemplo mais consistente, sobretudo, devido ao amparo normativo, foi à criação dos Mosaicos se Áreas Protegidas no SNUC em 2000.

Os mosaicos são estratégias de gestão territorial da conservação ambiental, sobretudo, por não tratá-la apenas como dimensão técnica ou biológica. Por outras palavras, subjaz a proposta de reconhecimento dos mosaicos o intuito de compreender os sistemas ecológicos integrados a dinâmicas econômicas, políticas e culturais. Portanto, é uma estratégia de gestão territorial da conservação, pois buscam explicitar a complexidade das interpelações entre sociedade e natureza de uma determinada região.

Ao colocarmos em evidência o exemplo empírico do MSVP, sobretudo, ao destacar as intenções do seu Plano DTBC em consolidar a gestão integrada das diversas UCs, ficou em evidência a necessidade de um pacto institucional e político sobre as estratégias da conservação. A gestão integrada pressupõe cooperação administrativa entre gestores das UCs, instituições e sociedade civil a fim de assegurar a sustentabilidade dos recursos e a consolidação das Áreas Protegidas. A ideia de gestão integrada no MSVP visa colocar em debate e procurar soluções para problemas específicos, como, por exemplo, a questão do desflorestamento do Cerrado por meio da produção de carvão vegetal e da expansão do agronegócio; além de criar mecanismos de combate e controle de incêndios; mas, ao mesmo tempo, visa questões de cunho mais geral como o levantamento fundiário e o fortalecimento de pesquisas referentes às UCs do mosaico.

Conforme destacamos ao longo do texto, a ideia subjacente aos Mosaicos de Áreas Protegidas é justamente a de romper com este efeito de ilha construído em torno das UCs. Nos mosaicos, as UCs são consideradas como partes integrantes dos sistemas culturais, econômicos e ecológicos, enfim, considerando que as UCs matem relações variadas com seu entorno, é preciso integrá-lo as estratégias de planejamento e desenvolvimento em contexto regional. 
Mas para que isso se torne concreto é preciso enfrentar as dificuldades de compatibilizar os diversos anseios e interesses que se coloca entre a conservação da natureza e as estratégias desenvolvimento, os desafios da gestão integrada e participativa, isto é, o desafio de se criar mecanismos no qual tanto os gestores das UCs, sociedade civil e as populações atingidas pela criação de unidades possam efetivamente participar/definir as estratégias de conservação.

\section{REFERÊNCIAS}

ACOSTA, Alberto. O bem viver: uma oportunidade para imaginar mundos. Tradução de Tadeu Breda. São Paulo: Editora Elefante, 2015. p. 264

Boletim da Cooperação Brasil-França sobre Áreas Protegidas. A construção da cooperação. Brasília, Edição especial, nº. 9, p. $1-8$, abr./mai., 2010.

BENSUSAN, Nurit. Conservação da biodiversidade em áreas protegidas. Rio de Janeiro: Editora FGV, 2006. p.176

BONNIN, Marie; VELUT, Sébastien. La contribución del concepto de Reserva de la Biosfera al desarrollo sustentable: un enfoque comparado Francia-Chile. In: Desarrollo Sustentable, Gobernanza y Derecho: Jornadas de Derecho Ambiental, IV, 2008. Anais... Santiago-Chile, 2008. p.1-23.

BOVÉ, José. Precisamos acabar com a ideologia do progresso. In: LLENA, Claude (Org.). Desfazer o desenvolvimento para refazer o mundo. Tradução de José Maria de Almeida. Cidade Nova: São Paulo, 2009. p.19-22. p. 296

BRASIL. Sistema nacional de unidades de conservação da Natureza-SNUC. Lei 9985 de 18 de julho de 2000; Decreto n ${ }^{\circ}$ 4340 de 22 de agosto de 2002. Ed. Aumentada. Brasília: MMA \BF, 2000.

BRASIL. Regulamenta artigos da Lei n ${ }^{\circ}$ 9.985, de 18 de julho de 2000. Decreto no․ 4340 de 22 de agosto de 2002. Ed. Aumentada. Brasília: MMA \SBF, 2000-2002.

BRASIL. Ministério do Meio Ambiente. Plano Estratégico Nacional de Áreas Protegidas - PNAP. Decreto $n^{\circ} 5.758$, de 13 de Abril de 2006. Brasília: MMA, 2006.

COSTA, Cláudia; HERRMANN, Gisela. Gestão integrada de áreas protegidas: uma análise de efetividade de mosaicos. Brasília-DF, WWF - Brasil, 2015. p.85

DELELIS, Caroline Jeanne; REHDER, Tatiana; CARDOSO, Thiago Mota. Mosaicos de áreas protegidas: reflexões e propostas da cooperação franco-brasileira. Brasília: Ministério do Meio Ambiente - MMA; Embaixada da Franca No Brasil CDS; UnB, 2010. p.150

DIEGUES, Antonio Carlos Santana. O mito moderno da natureza intocada. 3 ed. São Paulo: Editora Hucitec, 2001. p.169

FUNATURA. Relatório de cumprimento do objeto parcial - RCO: Projeto Mosaico Sertão Veredas-Peruaçu MMA/FNMA 106/2005. Brasília: Funatura, 2011.

FUNATURA. Plano de desenvolvimento territorial de base conservacionista. Brasília: Funatura, 2008. 
GONÇALVES, Gilberto Lamoglia. Modelos de gestão participativa para Unidades de Conservação federais de uso indireto: o caso do Parque Nacional da Tijuca. 2000. 206 f. Dissertação (Mestrado em Ciência Ambiental) - Instituto de Geociências, Universidade Federal Fluminense, 2000.

MMA/FNMA. Edital nº. 01/2005. Mosaicos de Áreas Protegidas: uma estratégia de desenvolvimento territorial com base conservacionista. MMA/ FNMA: Brasília, 2005.

TAMBELLINI, Manuela. Mosaico como modelo de gestão de áreas protegidas: análise conceitual e processos de implantação. 2007. 121 f. Dissertação (Mestrado em Ciência Ambiental) - Programa de Pós-Graduação em Ciência Ambiental, Universidade Federal Fluminense, 2007.

TOLEDO, Victor. M. ¿Áreas naturales protegidas o estrategia bioregional? Gaceta Ecológica, México, n. 77, p. 67-83, out./dez., 2005.

SANTO, Cesar Victor do Espírito. Construção e Execução do Plano de Desenvolvimento Territorial com Base Conservacionista do Mosaico Sertão Veredas - Peruaçu. Disponível em:

www.redemosaicos.com.br/arquivos_dados/arq.../mmidia-id-62.pdf. Acesso em: janeiro de 2015.

WAHREN, Juan. La naturaleza en disputa en América Latina: la encrucijada civilizatoria entre el "desarrollo" y el "buen vivir" desde una mirada decolonial. Revista de Geografia, Recife, v. 33, n. 3, p. 6-28, 2016.

WEIGAND JR., Ronald. Que es desarrollo con base conservacionista. Brasília: MMA, 2005. p.15 